\title{
A influência do toyotismo na reestruturação do sistema capitalista: uma análise gramsciana
}

\author{
João Paulo Santos Araujo'
}

\section{Resumo}

Este artigo tem como preocupação a análise do modelo produtivo Toyotista no mundo pós-Fordista. A intenção é provar que o modelo, desde a sua origem, tem características semelhantes às que deram origem ao Fordismo nos Estados Unidos e foi fundamental na substituição deste em sua decadência pelo modelo pós-Fordista. O estudo retrata a influência de tal modelo sobre aspectos socioculturais, políticos e econômicos na sociedade japonesa e, posteriormente, a replicação de seus elementos além das fronteiras do Japão. Além disso, o Toyotismo é aqui apresentado como o modelo que reestruturou o sistema capitalista e o manteve como sistema de acumulação vigente e a base da flexibilização da era pós-Fordista. Para isso, serão utilizadas as ideias de Gramsci como base teórica para a discussão por acreditar que sua preocupação com a extensão das transformações dentro do ambiente de trabalho se estende às esferas sociais, políticas e econômicas da sociedade. A análise feita pelo autor sobre o Fordismo estadunidense servirá de alicerce para a abordagem do Toyotismo e suas consequências nessas esferas. $\mathrm{O}$ escrutínio aborda elementos produtivos, mudanças e características do trabalhador e a influência dessas mudanças nas políticas de governo. O ponto de partida para a análise é o Fordismo nos Estados Unidos e o nascimento de um novo sistema de acumulação por esse modelo ser o predecessor e a base do Toyotismo japonês. Em seguida, o declínio do modelo e a crise de rigidez serão postos em foco para, por fim, apresentar o Toyotismo, a flexibilização da produção e as mudanças que o modelo trouxe ao sistema produtivo e social no mundo.

Palavras-chave: Toyotismo. Fordismo. Modo de produção. Flexibilização da produção.

\footnotetext{
${ }^{1}$ Mestre em Relações Internacionais pela University of Kent, Canterbury, Reino Unido.
} 


\section{Fordismo}

A análise da importância da produção automobilística no mundo capitalista pode esclarecer muitas dúvidas sobre a permanência desse último como principal modelo econômico vigente. Desde a substituição da produção artesanal - na qual os automóveis eram artigos para a camada social de maior poder aquisitivo - até o início da popularização do uso do automóvel e a produção em grande escala, os modos de acumulação e a produção tiveram que conviver com crises. Por conseguinte, para manter o sistema em harmonia com as necessidades impostas pelas novas demandas dos consumidores e também para uma melhor aplicação dos recursos disponíveis no processo produtivo, essas crises tiveram de ser contornadas. Grande parte das mudanças do setor industrial foi proporcionada pela evolução tecnológica e pelos meios utilizados na produção automobilística, já que os modelos produtivos e gerenciais foram sendo replicados em vários outros setores. Tal indústria foi uma das pioneiras no desenvolvimento dos meios de produção, organização e divisão do trabalho.

As mudanças procedimentais não são o cerne desta análise, mas carregam em si uma importância ímpar no tocante ao surgimento de novas estruturas sociais, econômicas e políticas para o sistema produtivo e de acumulação atual. A transição de um modelo artesanal de produção para um modelo Fordista e, posteriormente, para um modelo pós-Fordista, marca não só uma era tecnológica, mas também uma variação comportamental em termos sociopolíticos. A sociedade reage de acordo com a situação socioeconômica e, de certa forma, sucumbe aos novos modelos produtivos por necessidades temporais. Já os governos, com seus interesses desenvolvimentistas, investem no crescimento das indústrias nacionais por meio de políticas públicas.

Em termos teóricos, podemos afirmar que o capitalismo passa sempre por um ciclo de conjuntura. Esse conceito, segundo Paul Singer (1987) em sua análise, caracteriza o capitalismo como capaz de passar por mudanças constantemente, dependendo da necessidade que enfrenta.

As supramencionadas transições ocorrem sempre em um período em que o sistema capitalista sofre crises estruturais, com a ameaça socialista durante o pós-Primeira Guerra (no caso do Fordismo) e com a Guerra Fria (pós-Fordismo). 
Além disso, outros fatores marcantes dessas crises serão aqui apresentados, como a crise de superprodução do início do século e as crises do petróleo da década de 1970, que colocaram em dúvida a continuidade do mesmo no século XX. Uma constante reformulação nos moldes da produção proporcionou o triunfo do sistema e, como visto atualmente, sua maior influência na economia mundial.

É justamente a capacidade de reformulação do capitalismo que define a terminologia adotada por Singer. O autor destaca que é a regulamentação na criação de políticas criadas junto às necessidades temporais de determinado período socioeconômico que mantém a harmonia entre as esferas sociais, econômicas e políticas (SINGER, 1987). Assim, como será explicitado no decorrer desta pesquisa, os processos produtivos contribuem de maneira decisiva para a conservação do sistema. Eles foram, na minha interpretação, cruciais para a adequação às novas demandas e problemas desenvolvidos com o passar dos anos. O argumento que segue é para, além de comprovar o caráter cíclico da restauração do sistema capitalista no pós-guerra, explicitar a importância do sistema Toyota de produção depois das crises da década de 1970. Para cumprir com esse objetivo, o pensamento Gramsciano sobre o Fordismo nos Estados Unidos e a busca pela racionalização serão os pontos de partida para a análise.

O início da era Fordista, ao fim da primeira Guerra Mundial, teve a seu favor a mudança na tecnologia industrial da época. A intenção de produzir veículos em série, de uma forma mais sucinta e menos dispendiosa, findou por criar a racionalização do processo de produção. Essa observação não é nova, já que em outros períodos históricos, principalmente desde a Revolução Industrial, a intenção do crescimento do volume da produção e a diminuição dos custos eram aparentes. No entanto, as consequências diretas ao desenvolvimento do Fordismo resultaram num novo sistema de acumulação de proporções mundiais em um curto espaço de tempo.

A partir dos bons resultados alcançados pela Ford Motors, a busca pela racionalidade na produção começa a ser prioridade para os engenheiros de produção e empresários. Cria-se, portanto, um pacto social onde a sociedade interage com o um determinado sistema produtivo de modo a fazê-lo funcionar e triunfar sobre outros. Tal pacto nem sempre é tácito e depende, em grande parte, da aceitação social das medidas impostas pelas empresas e, em alguns casos, políticas de governo. 
Tal interpretação nos remete à ideia de racionalidade tecnológica contida nas ideias de Max Weber, e desenvolvida por Habermas. O conceito foi proposto, segundo Habermas, com a intenção de estabelecer uma relação entre sociedade e desenvolvimento tecnológico. Para ele, a racionalidade tecnológica é a forma de legitimar a dominação dos indivíduos pela dependência social das tecnologias criadas (HABERMAS, 2001). Primeiramente, o foco se dá apenas nos meios em que a cientificidade da administração colocou em voga a forma de produção dentro da indústria. Isso porque o modelo anterior à revolução industrial nos remete a um tipo de sociedade que não há a priori intenção de se montar modelos industriais. Nesse processo de mudança, é importante ressaltar que, fundamentalmente, a transformação e o maior conhecimento dos recursos naturais fazem parte da proposta, já que tais fatores correspondem às fontes para o desenvolvimento de novas tecnologias e proporciona a subordinação dos indivíduos no tocante às praticidades cotidianas desde os primórdios.

A racionalização das tecnologias - que na sua essência se relaciona com a comodidade e o início da dependência tecnológica - e a sujeição ao modelo de administração científica de Frederick Taylor levaram Henry Ford à conclusão de seu modelo de automóvel e ao processo produtivo do mesmo. A decomposição do trabalho na fábrica e a fragmentação da produção mostravam, em um curto período de tempo, que a produção automobilística de Ford estava um patamar acima das demais empresas, fator esse que causou uma revolução no ramo industrial ao qual pertence. Pode-se afirmar, portanto, que o Fordismo e o Taylorismo, em conjunto, foram os marcos da racionalidade corporativa do trabalho na produção automobilística da época (GOUNET, 1999).

No entanto, e esse é o objetivo deste escrutínio, a racionalização da produção acarretou consequências muito além daquelas mudanças vistas dentro das premissas fabris. Por tal motivo, o termo Fordismo aqui mencionado se trata de um sistema mais amplo e inclui os mecanismos de produção e consumo em massa baseado no desenvolvimento de uma população economicamente apta a consumir as mercadorias que produz. O Taylorismo/Fordismo - modelo ligado ao processo administrativo fortemente influenciado pelos Princípios de Administração Científica, de F. W. Taylor (HARVEY, 1993) aqui é deixado de lado para que o foco seja dado ao Fordismo como modelo de produção e forma de acumulação. 
A transformação dos elementos do trabalho e da produção mudou o panorama mundial. A verticalização da produção - monopolização de todas as etapas do processo - pelos industriais criou grandes corporações, sendo que a grande maioria era lotada nos Estados Unidos. Esse tipo de produção tinha por base a grande especialização dos trabalhadores e tarefas monótonas de caráter puramente físico. $\mathrm{O}$ fator relevante nesse aspecto é que as funções realizadas requeriam muito pouco dos empregados, o que os condicionava a uma baixa (ou praticamente inexistente) qualificação para o tipo de função designada. Somado a esse fator, temos as máquinas que, mesmo modernas na época, representavam um maquinário altamente limitado a desempenhar funções específicas, ou seja, assim como os trabalhadores, possuíam pouca versatilidade.

Por tal motivo, Henry Ford encontrou dificuldades em contratar funcionários e se viu obrigado a trazer mão de obra imigrante para as linhas de montagem. Isso porque os trabalhadores que possuíam oportunidade de escolher entendiam o processo artesanal como sendo mais qualificado e menos constrangedor, levandose em consideração que os trabalhadores atuantes no ramo possuíam status de mão de obra qualificada. A solução encontrada foi de dobrar os honorários recebidos pelos trabalhadores, passando a receber cinco dólares por cada jornada de oito horas de trabalho, com o objetivo único de trazer para a Ford a quantidade necessária de trabalhadores para suprir as necessidades de produção. Foi inevitável que as empresas concorrentes - principalmente as menores - perdessem espaço, inclusive entre os trabalhadores, e tiveram que se adequar também ao novo salário pago aos seus funcionários (GOUNET, 1999).

A partir desse momento, surge nos Estados Unidos uma classe trabalhadora com grande poder aquisitivo. Com o aumento na produção de veículos e os baixos preços cobrados, ocasionou um maior acesso à compra de automóveis por parte dos estadunidenses. O crescimento do poder de compra do trabalhador resultou na inserção de uma nova população consumidora de automóveis nos planos de venda. O precursor do modelo tinha consciência que seus trabalhadores eram potenciais consumidores de seus automóveis e trabalhava com a produção estrategicamente montada com trabalho em apenas cinco dias semanais. Os outros dois dias restantes serviriam para o descanso de seus funcionários e para que eles tivessem tempo de desfrutar de seus bons sa- 
lários, de preferência dentro de um carro produzido na Ford Motors. A transformação do trabalhador seguia e foi alvo de comentários de Antonio Gramsci, em uma sessão exclusiva intitulada Americanismo e Fordismo, que considerou a racionalização da produção como a aliança entre "a força (destruição do sindicalismo operário de base territorial) com persuasão (altos salários, diversos benefícios sociais, habilíssima propaganda ideológica e política) e conseguindo centrar toda a vida do país na produção” (GRAMSCI, 2001, p. 247). Em outra passagem, Gramsci acrescenta que:

$\mathrm{Na}$ América, a racionalização do trabalho e o proibicionismo estão indubitavelmente ligados: as investigações dos industriais sobre a vida íntima dos operários, os serviços de inspeção criados por algumas empresas para controlar a "moralidade" dos operários são necessidades do novo método de trabalho. (GRAMSCI, 2001, p. 266)

Tais medidas foram tomadas pela Ford Motor Company para um maior controle extrafábrica dos trabalhadores, pois além de receberem altos salários, os operários eram responsáveis por grande parte do consumo da empresa. Portanto, as medidas denominadas por Gramsci como proibitivas sempre visavam o melhoramento do desempenho do trabalhador dentro da linha de montagem, transformação do trabalhador em um indivíduo social modelo e torná-lo um consumidor em massa. Acontece, portanto, a formatação do funcionário além dos muros da fábrica.

Chamo a atenção para o fato de que Gramsci não presenciou a ascensão do Fordismo ao topo. Publicado em 1934, a obra em que ele apresenta dados relacionados ao Fordismo mostra ainda um sistema em desenvolvimento. A previsão feita por uma mundialização do modelo era feita em meio à grande expansão dele, principalmente no continente europeu. Porém, em sua análise, Gramsci aponta o êxito de Ford apenas pela disposição cultural estadunidense no que se refere aos meios de produção e de vida na América do Norte. Para ele, a Europa passaria por grandes dificuldades na adoção de tal forma de produzir veículos por possuir uma classe parasitária ${ }^{2}$ em sua formação social.

\footnotetext{
${ }^{2}$ Gramsci utiliza esse termo em Cadernos do Cárcere: temas de cultura, ação católica, americanismo e fordismo para caracterizar a classe burguesa europeia. Para ele, essa classe é a responsável pelo atraso e a dificuldade de implantação do Fordismo nos países europeus.
} 
A diferença existente, quando comparamos os europeus aos estadunidenses, na posição do autor, foi devido às raízes históricas dos últimos e a "uma composição demográfica racional" afastada de tradições que colocassem alguma classe sem nenhuma função essencial na produção. Para ele, essa seria a tônica do desenvolvimento de um consumo em massa e a transformação do trabalhador. $\mathrm{Na}$ opinião de Harvey, em uma das interpretações do pensamento de Gramsci, esse autor utiliza-se de uma citação do próprio para caracterizar o modelo fordista como sendo "maior esforço coletivo até para criar, com velocidade sem precedentes, e com uma consciência de propósito sem igual na história, um novo tipo de trabalhador e um novo tipo de homem" (HARVEY, 1993, p. 121). Podemos, nesse aspecto, concluir que a produção do novo homem para Gramsci, e no entendimento de Harvey, seria o fato de tais medidas proibitivas causarem impactos sociais e individuais numa sociedade pré-disposta às mudanças.

Com a crise financeira e de superprodução de 1929, surgiram estratégias políticas e econômicas as quais fizeram com que os norte-americanos retomassem o crescimento econômico para, logo a seguir, dominar a produção industrial mundial. As políticas do New Deal e a aplicação do pensamento Keynesiano tiveram o apoio de várias camadas da sociedade estadunidense incluindo intelectuais, empresários e donos de indústrias e sindicatos (ROBINSON, 2004, p. 42). Foi desse modo que o Estado agiu em conjunto com as aspirações das companhias e foi o órgão regulamentador que proporcionou políticas fiscais e monetárias no setor público.

Primeiramente, o Estado, nesse caso, impulsiona o sistema produtivo a funcionar sozinho e, com uma infraestrutura favorável, torna prática e necessária a utilização de um automóvel no cotidiano. Essa suposta dominação criada pela comodidade e a facilidade em se obter um automóvel ${ }^{3}$ agiu como uma estrutura para uma ajuda mútua entre a venda de automóveis, os grandes lucros das empresas e a existência de um sistema que buscava o pleno emprego e tinha por base o consumo em massa. O crescimento da produção colocou mais empregos à disposição da população, assim como o desenvolvimento infraestrutural também demandou muita mão de obra em diversos setores da economia (ROBINSON, 2004).

\footnotetext{
${ }^{3}$ Neste caso, podemos relacionar essa dominação como sendo um exemplo prático da interpretação de Habermas sobre a racionalidade tecnológica de Weber, onde a legitimação se dá pelos fatores comodidade e facilidade em se obter um automóvel.
} 
O crescimento norte-americano causou impacto na estrutura econômica mundial. Assim, ganhou força a "ideologia produtivista” proposta por Rupert, que defende a atuação dos governos para criar um ambiente favorável à produção para manter altos níveis de produtividade através do consumo em massa (RUPERT, 1995, p. 29). Nasce aí o "compromisso da classe Fordista” que Lipietz e Robinson mencionam em seus estudos. Esse compromisso é baseado em incentivos às companhias, arrecadação e redistribuição de renda além da autorregulação da economia para assegurar um crescimento em longo prazo por meio do pleno emprego (ROBINSON, 2004, p. 42; LIPIETZ, 1987). Mesmo com diferentes impactos nas diferentes economias e sociedades em que o modelo foi aplicado a utilização quase que universal - e nesse caso é importante mencionar que até mesmo a União Soviética e suas diretrizes socialistas foi adepta - deu ao Fordismo o status de modo de acumulação universal. No entanto, cabe ressaltar, foi no ambiente de livre mercado e na criação de métodos para a compra de matéria-prima de baixo custo e venda de produtos industrializados que o sistema se desenvolveu. Aos poucos os mercados internacionais foram sucumbindo às mudanças e aceitando as novas normas impostas para também desenvolverem sua capacidade comercial e produtiva. A implicação disso foi a notória liderança estadunidense na produção industrial que ajudou o país a sobrepor a crise de superprodução da década de 1920.

Nesse ponto, o pensamento Gramsciano e a importância dada por ele às mudanças produtivas mostram a característica mundial da produção industrial e os níveis por ela atingidos. Do período entre guerras até o fim da década de 1970 a produção e o consumo em massa ditaram as relações de produção e recaracterizaram o capitalismo, com o modo Fordista de produção e acumulação. É a influência das mudanças dentro do ambiente de trabalho no contexto sociopolítico e econômico.

\subsection{Declínio}

De fato, a preponderância do modelo Fordista veio abaixo com a sequência de crises na década de 1970. Para Harvey, já em 1960 o Fordismo apresentava problemas em seu cerne, os Estados Unidos. Segundo o autor, a rigidez, os altos custos com estoques e a mudança na demanda dos consumidores expuseram 
as fragilidades produtivas do sistema. É certo que nesse período houve grandes avanços na área de transportes e a exportação continuava alimentando grande parte das corporações, assim como as suas subsidiárias continuavam obtendo bons lucros. Mas, o fato relevante do período é que, mesmo com o aumento da produção no mundo inteiro, as empresas estadunidenses concorriam com um crescente mercado internacional cada vez mais preparado para a competição nas exportações de insumos industrializados. Harvey destaca ainda que, com o fim das reconstruções europeia e japonesa - planos Marshall e Colombo, respectivamente - o mundo passou a ter novamente uma multipolaridade na produção fabril. Acrescentou-se a isso a transnacionalização da produção política de substituição das exportações dos países em desenvolvimento, a criação do mercado dos eurodólares em todo o mundo, e o crescimento da inflação nos Estados Unidos devido à emissão de moeda em excesso para pagar as dívidas das políticas sociais de Kennedy e a Guerra do Vietnã (HARVEY,1993). O Fordismo ganhava outro vilão às suas aspirações quando, no período de 1968-72, uma série de greves dos trabalhadores parecia tornar o sindicalismo imbatível nos países industrializados. As concessões trabalhistas estavam trazendo cada vez mais prejuízos às empresas $\mathrm{e}$ esse fator evidenciava a fragilidade do sistema de acumulação vigente já que muitas das grandes corporações mostravam saúde financeira complicada.

A situação do modelo Fordista ainda se agravaria com a resolução imposta pelos membros da OPEP em 1973. A decisão de dobrar o preço do barril do petróleo - combustível da produção industrial e dos automóveis -, além de iniciar embargos à exportação do produto aos países do ocidente em represália ao apoio de tais países a Israel no conflito árabe-isralense de Yom Kippur; foi mais um fator decisivo em uma crise que se estendia por alguns anos (HARVEY, 1993).

Assim sendo, as fábricas passaram a ter problemas de abastecimento e se queixavam de um consequente aumento dos preços dos produtos finais, e, no caso específico da produção automobilística, um aumento no custo do combustível dos automóveis. Diante de tais dificuldades, o sistema de produção e acumulação entra em colapso e, para se sustentar, o capitalismo sofreu mais uma mudança.

O resultado disso foi o desenvolvimento de novas tecnologias e um modelo menos rígido àquele proposto pelo Fordismo. $\mathrm{O}$ chamado pós-Fordismo, portanto, caracteriza-se principalmente pela flexibilização das relações de produção - e 
da produção em si -, novos meios de fluxo de mercadorias e capital e, sobretudo, inovações organizacionais (HARVEY, 1993, p. 147). Ainda que autores como Dohse, Jürgens e Malsch (1985, p. 115-146) usem de argumentos contrários ao fim do modelo Fordista e ao surgimento de um modelo pós-Fordista, as mudanças no sistema levam a crer que a produção e o consumo em massa claramente perderam espaço com o passar dos anos. Nesse aspecto, é importante ressaltar que, ao definir o Fordismo como um modelo de acumulação, as referidas transformações indicam que um novo modelo sobrepôs o antigo. O modelo antigo era rígido e ultrapassado e pouco conseguia lidar com as novas demandas tecnológicas, de mercado e financeiras. Portanto, o Fordismo, a partir da década de 1980, foi cedendo espaço a outros modelos de acumulação.

\section{Toyotismo}

A existência de mais de um modelo pós-Fordista, a meu ver, cria uma gama de interpretações no tocante às estruturas econômicas e sociais num contexto onde a rigidez da produção e dos meios de acumulação - nesse aspecto eu incluo políticas de governo - perdeu força. Assim como no modelo Italiano - Terceira Itália - e o Volvoísmo sueco, o processo que culminou no Toyotismo teve características socioeconômicas preponderantes para sua consolidação. No entanto, os dois primeiros modelos se diferenciam do Toyotismo por tornarem-se apenas modelos produtivos e de pequeno impacto social. É importante, portanto, seguir o raciocínio anterior - em relação ao Fordismo - e caracterizar o Toyotismo não só como um modelo produtivo, mas também como uma mudança social, política e econômica do Japão. Sendo assim, o foco da análise passa a ser a utilização dos conceitos Gramscianos da análise anterior para interpretar as mudanças e peculiaridades do modelo japonês com relação à propensão desse país em criar um método que atravessou as fronteiras de seu território.

Historicamente, podemos atribuir o nascimento do Toyotismo às dificuldades de se implantar o Fordismo no Japão. A demanda naquele período era diferenciada e o país possuía características muito distintas às das sociedades ocidentais. $\mathrm{O}$ incentivo do Estado mostrava uma tentativa de se manter uma indústria forte, mas o resultado da guerra e das bombas atômicas lançadas sobre seu território 
colocaram o Japão à mercê de políticas outorgadas pelas nações vencedoras do conflito. O plano de reestruturação do país intencionava, além de outras coisas, ocidentalizar o padrão de consumo do país. Entretanto, essa ação não obteve êxito, já que, a implantação de um modelo puramente ligado à produção em massa exigia o complemento do consumo em massa, porém, uma população que reagia a um conflito como a Segunda Guerra e, com os ônus sofridos, não teria poder aquisitivo para responder de tal forma aos estímulos de consumo.

Womack aponta que as necessidades territoriais foram de grande importância para a adaptação do modelo de Ford às necessidades japonesas. O autor destaca cinco dificuldades enfrentadas pelos japoneses na jornada da produção de automóveis, iniciando pela limitação do mercado doméstico e a variedade de demandas, fator que obrigava a fabricação de um automóvel para cada tipo de consumidor:

Carros de luxo para autoridades governamentais, caminhões grandes para transportar mercadorias, caminhões pequenos para os agricultores menores e carros pequenos adequados para as cidades populosas e para o alto custo do combustível no Japão (WOMACK, 1992, p. 40).

O terceiro ponto foram os empecilhos causados pela influência dos Estados Unidos nas leis trabalhistas do país. Para Womack, após a aprovação das novas leis, os trabalhadores passaram a ter direitos múltiplos e seria dispendioso ao empregador demitir funcionários, garantindo-lhes um emprego quase vitalício. Além disso, os sindicatos passaram a ter uma maior proteção em termos legais e defendiam todas as esferas da empresa (os trabalhadores de chão de fábrica e os administrativos), garantindo, por exemplo, uma divisão dos lucros da empresa em forma de bônus periódicos. O último argumento relacionado aos funcionários era a dificuldade em se encontrar o que Womack chama de "trabalhadores-hóspedes", ou seja, trabalhadores estrangeiros que estariam dispostos a oferecer mão de obra barata e se submeter às longas horas de trabalho dentro da fábrica, já que nos outros países que adotaram o sistema esse tipo de trabalhador correspondia a uma parcela considerável do total.

As outras duas razões são relativas ao mercado exterior e à competitividade. A economia japonesa foi devastada pela guerra e isso mostrava que o país não teria condições de importar maquinário de alta tecnologia para industrializar-se 
nos moldes ocidentais. As empresas concorrentes eram grandes corporações que, além de terem a intenção de infiltrarem-se no mercado Japonês, eram dotadas de muitos recursos para a defesa de seus mercados, dificultando assim o acesso dos produtos japoneses.

A tentativa governamental de incentivar as indústrias japonesas naquele período era veemente. Cada vez mais, políticas desenvolvimentistas e intervenções estatais foram sendo tomadas. Assim como no ocidente, a anteriormente mencionada ideologia produtivista, proposta por Rupert, foi a aposta japonesa para o desenvolvimento econômico.

Em uma das medidas criadas para desenvolver empresas competitivas, o Estado japonês, através do MITI (Ministério do Comércio Exterior e Indústria), propôs, nos anos 1950, a fusão das doze maiores empresas fabricantes de automóveis em uma ou duas empresas grandes para fazer frente às grandes de Detroit - General Motors e Ford Motors -, sendo que elas não deveriam competir umas com as outras. As grandes corporações seguiriam os moldes das empresas norteamericanas e receberiam total apoio governamental para o crescimento interno e externo. Apesar disso, as empresas japonesas não seguiram as instruções do MITI e, segundo Womack, isso foi preponderante para o êxito dessas companhias. Isso porque foi da individualidade e da relação entre pequenas, médias e grandes empresas que o processo de reestruturação seguiu. Porém, antes de discutir a relação entre tais empresas, me preocupo em apresentar as condições das relações de trabalho no Japão.

O primeiro ponto a ser ressaltado para explicar o desenvolvimento industrial japonês aqui será defendido pela configuração geográfica de seu território e das características da mão de obra, já que o país possuía, e ainda possui, grandes limitações referentes às matérias-primas. De fato, o Japão não teria condições naturais de manter uma indústria forte apenas com o que se extraía internamente, o que culminou na grande dependência da importação de matéria-prima externa. Max Derruau destaca:

O Japão quase que só se basta a si mesmo no tocante a pequeno número de matérias-primas, como o enxofre, as piritas, os minerais de cromo, de chumbo, de zinco, de cobre, de prata e de ouro. Ele não assegura o seu próprio abastecimento em carvão senão na proporção de $3 / 4$ [...] A produção nacional 
não fornece o suficiente, a não ser em quantidades vulgares. O país carece, seriamente, de minérios de ferro e sucata, de todos os minérios não ferrosos, com exceção dos que foram citados atrás, principalmente de bauxita. Igual carência se verifica no que tange ao petróleo, que não atende a $1 \%$ das necessidades nacionais, e às matérias-primas da indústria química mineral: nitrato, potassa, fosfato, sal. Até mesmo as florestas, ocupando, embora, quase $70 \%$ da superfície do território, somente abastecem o Japão na proporção de 3/4 (DERRUAU, 1970, p. 139).

O ambiente desfavorável deu oportunidade ao desenvolvimento tecnológico. Assim, os recursos naturais eram cada vez mais bem aplicados e a utilização eficaz tanto de matéria-prima quanto de recursos humanos promoveu o sistema Toyotista ao estágio de paradigma da produção no Japão. Essa transição pode ser explicada com as ideias de Gramsci quanto à "racionalização" e "moralidade". Foi uma nova transformação do trabalhador e do homem. A alusão é feita à realidade japonesa haja vista que, de uma maneira incisiva, os procedimentos desenvolvidos intrafábrica tiveram influência direta no comportamento da população fora do ambiente fabril. Esse último, por conter um caráter moral de uma tradicional sociedade como a japonesa, findou por criar e, posteriormente, legitimar as mudanças sociais e o desenvolvimento da cultura industrial no país.

O processo de racionalização ocorre, dentre outros motivos, pela demanda diferenciada e pela busca de um maior custo-benefício tanto para a produção quanto para o consumidor. Em tempos em que o preço do combustível vivia grande turbulência, disponibilizar produtos menos dispendiosos foi um diferencial na competição com as demais empresas. A preocupação com a diminuição do espaço e o tempo da produção, a gradual diminuição do tamanho e do gasto com os estoques - produção just-in-time - e o investimento na qualidade dos produtos por meio de um controle de qualidade exigente, baseados na intenção de reduzir os erros a zero, revigoraram o dispendioso e rígido Fordismo.

A função desempenhada pelos trabalhadores mudou. Isso porque, a esse ponto, os trabalhadores já não eram mais aqueles "apertadores de parafuso" das fábricas Fordistas e tornaram-se mão de obra qualificada. Assim sendo, a Toyota buscou o fim da especialização do trabalhador, o que culminou na polivalência dos operários e a melhor compreensão, por parte deles, das etapas da produção. Seria, 
portanto, assim como no Fordismo, uma tentativa de criar um novo tipo de trabalhadores, nem tão talentosos e polivalentes como os artesãos, e nem tão braçais quanto os trabalhadores ao modo Fordista.

Uma mudança como essa não é tão drástica a ponto de confundir muitas cabeças. O trabalho realizado continuava não exigindo muito das capacidades intelectuais dos empregados e estes apenas operavam máquinas que obedeciam a comandos simples. Porém, a diminuição dos espaços e o domínio sobre as etapas da produção proporcionaram aos funcionários a capacidade de fazer seu trabalho e, eventualmente, substituir algum outro funcionário que não se fez presente. Sobre a polivalência dos operários, Hirata e Zarifian (2009) expuseram:

A polivalência das funções dos operários [...] permite combinar competências na fabricação, na manutenção, no controle de qualidade, na administração dos fluxos. Essa combinação favorece curtos percursos de obtenção de informação e de intervenção dos trabalhadores da fábrica nos sistemas técnicos, sem que se tenha necessidade de apelar a níveis hierárquicos superiores ou a serviços conexos. O ganho de produtividade não apenas é evidente, como também essas práticas de organização criam, nos operários, uma familiaridade com os problemas técnicos e a busca de suas soluções.

As consequências disso são sentidas em muitos aspectos. A pressão psicológica sobre o trabalhador aumenta e cria-se um compromisso do indivíduo perante os seus colegas de trabalho. Aos poucos, cada funcionário passava a se identificar mais com a empresa e desenvolvia um sentimento de orgulho por representar a companhia. Os trabalhadores eram tratados com igualdade e mantinham uma relação muito próxima com todos os outros setores e trabalhadores da empresa. Além disso, eram estimulados a conversar e contribuir com o melhoramento dos processos produtivos, já que eram muito familiarizados com os procedimentos. $\mathrm{O}$ ambiente dentro da fábrica incentivava a relação amistosa entre os funcionários. Tais mudanças ocasionaram uma grande transformação no comportamento e perfil da mão de obra dentro da fábrica.

Durante a implementação do Toyotismo, os elementos força e persuasão foram igualmente decisivos na mudança do perfil dos trabalhadores. Com relação ao primeiro elemento, no Japão, assim como nos Estados Unidos, a classe sindical 
perdeu força. Aos poucos as próprias empresas criavam as associações de trabalhadores e regulamentavam as relações de trabalho. No caso japonês, a situação econômica do pós-guerra - alta taxa de desemprego e dependência de matéria-prima - e a reformulação das leis trabalhistas findaram por submeter os funcionários das empresas a situações de trabalho menos favoráveis.

O processo de persuasão utilizou o argumento das dificuldades financeiras e o corporativismo dos funcionários dentro da fábrica. No caso específico da Toyota Motors, o acontecimento histórico que marcou essa mudança foi a deposição do então presidente Kiichiro Toyoda por meio de uma greve dos trabalhadores. Após a mudança de gestão e a demissão de grande parte de seu pessoal, Eiji Toyoda sobrinho e sucessor de Kiichiro na presidência - foi o responsável por reformular a relação entre funcionários e a alta cúpula da empresa. Eiji teve em suas mãos um material humano reduzido - já que cerca de um quarto de seus trabalhadores foram demitidos - mas garantiu aos remanescentes que eles seriam funcionários Toyota por toda a vida. Tais trabalhadores passaram a ser parte da empresa e incorporaram aos seus salários parte dos lucros totais, além de terem direito a acesso vitalício aos benefícios oferecidos enquanto funcionários da fábrica, sendo que o salário era correspondente ao tempo de serviço na empresa. Em pouco tempo e devido ao sucesso da medida, esta foi amplamente difundida sobre outros setores industriais japoneses.

De fato, tais particularidades podem ser eventualmente atribuídas ao comportamento sociocultural japonês. No entanto, o que mais causou impacto no modelo de produção que se estendeu ao mundo se refere à relação existente entre as companhias e as suas subsidiárias. $\mathrm{O}$ tratamento preconizado pela Toyota com seus fornecedores se distanciou do modelo Fordista e foi, em parte, muito similar ao modelo italiano da Terceira Itália no qual grandes pequenas empresas forneciam componentes às grandes corporações. Diferentemente da produção em massa, a obtenção de componentes não se restringia somente à matéria-prima. Essa relação de afastamento da verticalização, a exploração das vantagens comparativas - principalmente no tocante às importações de matéria-prima - e a formação de joint ventures aproximaram o modelo Toyotista às necessidades temporais e, em decorrência disso, afastou a centralização Fordista de uma reestruturação que remeteria aos moldes antigos. 
As empresas contratadas eram, e ainda são, produtoras de tecnologia e gozam de uma grande importância no processo de montagem. Isso significa que o fornecedor deve ser um contribuinte para o processo e deveria fazer parte de um sistema conjunto em que o interesse mútuo traria o melhor resultado. Comumente os acordos entre Toyota e as empresas contribuintes - podemos chamar assim os fornecedores - eram feitos por um longo prazo e previam uma série de premissas. Ao contrário das empresas norte-americanas que entregavam os projetos prontos para a simples execução da construção das peças (medida que garantia um maior sigilo por motivos supracitados e mostrava a intenção de se manter grande parte dos componentes como sendo propriedade privada da empresa), a Toyota passou a estabelecer níveis de fornecedores que, de acordo com a importância na produção, faziam parte dos processos de desenvolvimento dos carros (WOMACK, 1992).

Ainda com relação aos fornecedores, a Toyota estimulou o intercâmbio de informações entre eles. Essa foi a forma encontrada de se criarem novos mecanismos e também de disseminar a chamada produção enxuta ${ }^{4}$ para as empresas, uma vez que foi detectado um grande número de desperdícios na produção deles. Outro fator relevante é que alguns dos fornecedores passaram a unir forças e fornecer peças entre eles. Assim, um fornecedor de nível um poderia produzir uma peça, usando diversos componentes, sendo que alguns deles ele traria de outra empresa fornecedora de nível dois. Nesse universo de ajuda mútua, todos passam a se beneficiar de alguma forma, inclusive em termos tecnológicos, e a Toyota não precisa contratar diretamente especialistas em determinadas áreas da produção, pois possuía fornecedores que agregavam valores ao seu produto.

De certo modo, essa mudança de relacionamento com as empresas subsidiárias causou um grande impacto na relação produtiva. Isso porque os benefícios oferecidos aos funcionários das grandes empresas acabaram por não atingir a camada de trabalhadores das empresas terceirizadas. Cria-se, daí, uma classe de trabalhadores que, por não ter um contrato direto com as grandes corporações, não goza de estabilidade nem tampouco acesso a regalias como, por exemplo, o bônus sobre o lucro da empresa.

\footnotetext{
${ }^{4}$ A denominação produção enxuta (lean production) é utilizada por Womack em A Máquina que mudou o mundo aproximando as mudanças promovidas pela Toyota Motors Company na produção de seus automóveis.
} 
Poucas empresas no Japão oferecem a possibilidade de o funcionário crescer internamente a ponto de ser efetivado em seu quadro de trabalhadores vitalícios. Muito pelo contrário, menos de quarenta por cento dos funcionários estão nessa situação, já que, custear um trabalhador de sua juventude - muitos deles são recrutados assim que terminam a escola secundária ou a faculdade - até a sua aposentadoria, aos 55 anos de idade, não seria viável para muitas manufaturas, principalmente para aquelas de menor expressão (FUTATA, 2005).

Mesmo com o país vivendo um bom momento econômico nas décadas de 1980 e 1990, as grandes empresas apostavam apenas em alguns operários para sustentar os cargos vitalícios. Isto em parte se deve por alguns momentos de instabilidade - e, em alguns casos, o fechamento de algumas delas - e pela contratação de empresas que atuam como empreiteiras de trabalho. Estas últimas lidam diretamente com o empregado, retirando toda a responsabilidade das fábricas e, em muitos casos, chegam a não respeitar os direitos trabalhistas. Essa relação entre as empresas, na época, foi inovadora, assim como as transformações de empregos e de tipos de trabalho foram preponderantes para o acontecimento. Além da criação de novos setores, novas obrigações e novos desafios eram impostos aos operários, e, conviver com o exército de reserva ocasionou instabilidade dentro das empresas.

A falta de interesse dos próprios japoneses em fazer parte de empresas menores causou uma crise na mão de obra no país, já que os nacionais os quais tiveram uma boa educação rechaçavam as funções secundárias nas empresas subsidiárias e pleiteavam vagas nas grandes corporações. Tal fato impulsionou o governo do Japão a incentivar a imigração e atrair os descendentes dos emigrantes japoneses do início do século - principalmente os que tiveram como destino a América do Sul - para o país.

A partir do sucesso e desenvolvimento tecnológico e econômico alcançado pelos nipônicos - atingindo o posto de segunda maior economia no mundo -, a replicação do Toyotismo e a busca pelo desenvolvimento tecnológico foi bem aceita além das fronteiras japonesas. A automação dos meios de produção passou a ser prioridade nas empresas, sendo comum o desenvolvimento e teste de novos equipamentos dentro das fábricas. Inovações desse tipo culminavam numa maior variedade de produtos e serviços, flexibilizando várias camadas produtivas - da extração de matéria-prima à conclusão do produto final. 
No caso japonês, Michiharu Sakurai (2009) destaca que a fase de expansão da produção japonesa passou por mudanças corporativas, ou seja, passou a objetivar o aumento de volume de produção após passar por um longo período de aumento na eficiência - referente a uma "maior rapidez na redução do tempo do ciclo de fabricação, entrega, rotação do estoque e processamento (economia de velocidade)" (SAKURAI, 2009). O resultado disso é que, em seu cerne, o Toyotismo primou pela criação e aperfeiçoamento de tecnologias e a consequência foi a expansão e a propagação delas para as outras empresas do segmento a qual pertence.

O alcance global do Toyotismo pode ser visto pela influência na estrutura industrial estadunidense. Segundo Kenney e Florida, a "flexibilidade estrutural" (KENNEY; FLORIDA, 1990, p. 233-252) do modelo japonês - que aqui interpreto como Toyotismo - invadiu os Estados Unidos e depois o Ocidente. Elementos como o fim dos grandes estoques, controle de qualidade e o just-in-time encontraram grande aceitação nas grandes companhias. As grandes economias - tanto o Estado quanto o capital privado - passaram a investir em desenvolvimento tecnológico e disseminaram a produção em diversas partes do mundo, principalmente nos países ditos do Terceiro Mundo. O grande aliado, nesse caso, foi a diminuição dos custos de transporte e a busca por mão de obra mais barata em economias nas quais o desemprego assolava e facilitava a terceirização e subcontratação de funcionários. Essa procura, principalmente após as crises do petróleo na década de 1970, causou um aumento no desemprego nos países desenvolvidos que viram os investimentos atravessarem as fronteiras, influenciados pelas facilidades na circulação de capital e a dificuldade em que os governos passaram a ter em regulamentar tais transações (HARVEY, 1993, p. 136-47).

O impacto das subcontrações e a mundialização da produção passou a ser uma característica constante das grandes corporações. A busca pela diminuição dos gastos da produção levou estas empresas a produções offshore, que replicaram cada vez mais o modelo japonês além das fronteiras de seus Estados. O fim do Fordismo e o inicio da era pós-Fordista foi a consagração da flexibilização e o marco do fim da rigidez. De certa forma, nas décadas de 1970 e 1980, a liderança japonesa nos métodos e nos meios de produção contribuiu para a reestruturação do modelo capitalista e fez com que as empresas japonesas tomassem, inclusive, o mercado estadunidense com a "revolução de alta tecnologia" (KENNEY; FLORIDA, 1993, p. 
50). O Toyotismo passou então a ser a característica que segregou as nações tecnológicas desenvolvidas das nações tecnologicamente atrasadas. Para as primeiras, as relações de trabalho favoráveis aos trabalhadores - como estabilidade de emprego, bons salários e participação efetiva nos lucros da empresa - e uma estrutura social estável. Já as segundas são corriqueiramente alvo das grandes empresas para montar suas subsidiárias justamente pela sua estrutura social frágil e fonte de mão de obra barata.

\section{Conclusão}

Parece-me adequado, guardando as devidas proporções, aproximar o Toyotismo do Fordismo. Nessa análise, considero o papel do Toyotismo como um modelo que, devido às novas demandas de mercado e a flexibilização, atingiu proporções mundiais e que, mesmo não atingindo o mesmo êxito do Fordismo, é um modelo que se mostrou apropriado às novas necessidades. De fato, outros modelos também foram importantes para o feito, porém, a internacionalização do modelo Toyotista e, principalmente o nascimento de empresas terceirizadas no processo produtivo, causaram um impacto socioeconômico muito grande nas economias em todo o mundo sejam elas desenvolvidas ou não.

É importante ressaltar que características como emprego vitalício e salários baseados pelo tempo de trabalho nas empresas não foram bem aceitos no ocidente. No entanto, a subcontratação, a descentralização e a busca pelo desenvolvimento tecnológico passaram a ser, assim como o Keynesianismo e a pleno emprego nos tempos de Fordismo, o objetivo das nações industrializadas com a intenção de aumentar o seu poderio econômico. Foi assim que, a meu ver, o Toyotismo se tornou o principal modelo de produção da era pós-Fordista. Além das características produtivas, o modelo se mostrou flexível e adequado às necessidades temporais do pós-crise na década de 1970.

No tocante às origens do sistema, podemos afirmar que os elementos levantados por Gramsci na sua análise do Fordismo se encaixam também no processo de estabelecimento do Toyotismo no Japão. No pós-guerra, o governo e a sociedade japoneses encontraram uma forma de se sobressair em meios produtivos e atingiram sucesso já na década de 1980. A atribuição desse êxito à composição 
social e econômica da sociedade foi aqui referida e, mesmo que por meios diversos, os resultados alcançados se assemelham quando se trata de desenvolvimento econômico, social, político, produtivo e tecnológico. Tais afirmações podem ser notadas nos processos de racionalização e moralização aqui descritos, assim como nos processos da utilização da força e da persuasão.

\title{
The influence of toyotism in the restructuring of the capitalism: a gramscian analysis
}

\begin{abstract}
This article is concerned to analyse the Toyotist way of production in the post-Fordist era. The intention is to prove that the model, since its origins, has similar characteristics to those that originated the Fordism in the United States and was fundamental in the substitution of the latter after its collapse to the post-Fordist model. The study presents the influence of the model in the socio-cultural, political and economical aspects on the Japanese society and, then, the replication of its elements beyond the borders of Japan. Furthermore, the Toyotism is here presented as the model that restructured the capitalist system and kept it in the core and the basis of the flexibilisation in the post-Fordist era. For that, I am going to apply Gramsci's theoretical framework in the discussion believing that the author's preoccupation with the extension of the transformation within the working environment influences also the social, political and economical spheres of the society. The analysis made by the author on the Fordism in the United States is going to be used as the framework to this study to interpret the Toyotism and its consequences in these spheres. The scrutiny contains productive elements, changes and characteristics of the workers and the influence of theses changes in governments' policies. The starting point is the analysis of the Fordism in the United State and the birth of a new accumulation system since this model is the predecessor and the basis of the Japanese Toyotism. Then, the decline of the model and the rigidity crises will be in the focus in order to present the Toyotism, the flexibilisation of the production and the changes that this model brought to the world's society and productive system.
\end{abstract}

Keywords: Toyotism. Fordism. Way of production. Flexibilisation of the production 


\section{Referências}

DERRUAU, Max. O Japão. Tradução de Hélio de Souza e Gisela Stock de Souza. São Paulo: Difusão Européia do Livro, 1970.

FUTATA, Marli Delmômico de Araujo. Breve análise sobre o toyotismo: modelo japonês de produção. Revista Espaço Acadêmico, n. 47, abr. 2005. Disponível em: $<$ http://www.espacoacademico.com.br/047/47cfutata.htm>. Acesso em: 15 ago. 2006.

GOUNET, Thomas. Fordismo e toyotismo na civilização do automóvel. Tradução de Bernardo Joffily. São Paulo: Boitempo, 1999.

GRAMSCI, Antonio. Cadernos do cárcere: temas de cultura, ação católica, americanismo e fordismo. Rio de Janeiro: Civilização Brasileira, 2001.

HABERMAS, Jürgen. Técnica e ciência como ideologia. Lisboa: Edições 70, 2001.

HARVEY, David. A condição pós-moderna. São Paulo: Loyola, 1993.

HIRATA, Helena; ZARIFIAN, Philippe. Força e fragilidade do modelo japonês. Estudos avançados, São Paulo, v. 5, n. 12, maio/ago. 1991. Disponível em: <http:// www.scielo.br/scielo.php?script=sci_arttext\&pid $=$ S0103-40141991000200011> Acesso em: 23 ago. 2009.

KENNEY, Martin; FLORIDA, Richard. Beyond mass production: The japanese system and its transfer to the US. Oxford: Oxford University, 1993.

KENNEY, Martin; FLORIDA, Richard. High-technology restructuring in the USA and Japan. Environment and Planning A, [S.1.], v. 22, p. 233-52, 1990.

KNUTH, Dohse, ULRICH, Jurgens; MALSH, Thomas. From "Fordism" to Toyotism? The social organization of the labor process in the japanese automobile industry. Politics and Society, [S.l.], v. 14, n. 2, p. falta paginação do artigo, 1985.

LIPIETZ, Alain. Mirages and miracles: the crisis of global fordism. Londres: Verso, 1987.

ROBINSON, William I. A theory of global capitalism: production, class and state in a transnational world. Londres: The John Hopkins University, 2004.

RUPERT, Mark. Producing hegemony: the politics of mass production and american global power. Cambridge: Cambridge University, 1995. 

Univ. Rel. Int., Brasília, v. 7, n. 2, p. 35-56, jul./dez. 2009
João Paulo Santos Araujo

SAKURAI, Michiharu. O passado e o futuro da contabilidade gerencial japonesa. Campinas, 2009. Disponível em: <http://libdigi.unicamp.br/ document/?view=111>. Acesso em: 20 ago. 2009.

SINGER, Paul. O capitalismo: sua evolução, sua lógica e sua dinâmica. São Paulo: Moderna, 1987.

WOMACK, James P., JONES, Daniel T.; ROOS, Daniel. A máquina que mudou o mundo. Rio de Janeiro: Campus, 1992. 